\title{
A review on applications of nanotechnology in the enhanced oil recovery part $A$ : effects of nanoparticles on interfacial tension
}

\author{
Goshtasp Cheraghian $^{1} \cdot$ Luky Hendraningrat $^{2}$
}

Received: 31 May 2015/Accepted: 14 December 2015/Published online: 22 January 2016

(C) The Author(s) 2016. This article is published with open access at Springerlink.com

\begin{abstract}
Chemical enhanced oil recovery is another strong growing technology with the potential of a step change innovation, which will help to secure future oil supply by turning resources into reserves. While Substantial amount of crude oil remains in the reservoir after primary and secondary production, conventional production methods give access to on average only one-third of original oil in place, the use of surfactants and polymers allows for recovery of up to another third of this oil. Chemical flooding is of increasing interest and importance due to high oil prices and the need to increase oil production. Research in nanotechnology in the petroleum industry is advancing rapidly and an enormous progress in the application of nanotechnology in this area is to be expected. Nanotechnology has the potential to profoundly change enhanced oil recovery and to improve mechanism of recovery. This paper, therefore, focuses on the reviews of the application of nano technology in chemical flooding process in oil recovery and reviews the application nano in the polymer and surfactant flooding on the interfacial tension process.
\end{abstract}

Keywords Nano particles · Flooding · Interfacial tension $\cdot$ Chemical oil recovery

Goshtasp Cheraghian goshtasbc@gmail.com

1 Young Researchers and Elite Club, Omidieh Branch, Islamic Azad University, Omidieh, Iran

2 Department of Petroleum Engineering and Applied Geophysics, NTNU, 7491 Trondheim, Norway

\section{Introduction}

Nanotechnology, through the use of nanoparticles, has provided a means of enhancing the rheological properties of fluids at ambient and elevated temperatures; though, detrimental effects set in above certain nanoparticle concentrations. Nanotechnology deals with the design, characterization, production and application of materials and devices based on nanometer scale [1]. Nanoparticles are particles with dimensions in the order of $1-100 \mathrm{~nm}$. They possess unique properties due to their small sizes, and greater surface area per unit volume [2]. Various nano-fluids can be designed by the addition of nanoparticles to different base fluids. The stability or dispersion of nanoparticles in solutions relies on the functionality (or surface activity) of the nanoparticles. To this end, the surfaces of nanoparticles are usually treated or functionalized; thereby putting shields around them. These shields hinder particle-particle interaction, and the possibility of nanoparticles aggregation is reduced. Nanotechnology in the petroleum industry has gained enormous interest the recent years, which is reflected in the amount of literature available. Nanoparticles for enhanced oil recovery (EOR) purposes seem gradually to become the cutting-edge technology [3].

Reservoir engineering, however, has received the most attention for nanotechnology applications. Several experiments have been conducted to investigate flow behavior of nanoparticle suspensions through porous media. Rodriguez et al. [4] investigated the migration of concentrated surface treated silica nanoparticles in sedimentary rocks. Kanj et al. [5] identified the usable size of nanoparticles in reservoir rocks through nano-fluid core flooding experiments. Using hydrophilic/hydrophobic synthesized nanoparticles, Zhang [6] made oil in water emulsions and stabilized $\mathrm{CO}_{2}$ foams with quite high stability. 
The nanotechnology has been widely used in several other industries, and the interest in the oil industry is increasing. Silica nanoparticles are the most widely tested, and have shown good EOR applications. Recently, studies have explored the potential of $\mathrm{Al}_{2} \mathrm{O}_{3}, \mathrm{MgO}, \mathrm{Fe}_{2} \mathrm{O}_{3}$ in addition to $\mathrm{SiO}_{2}$ nanoparticles. The results showed that some combinations have yielded better results than $\mathrm{SiO}_{2}$. Based on the current knowledge, it is expected that both chemical EOR and specifically micellar flooding will make huge benefits from nanotechnology and nano-emulsion in particular in the future [7]. Adding nanoparticles to fluids may significantly benefit enhanced oil recovery and improve well drilling, such as changing the properties of the fluid, wettability alternation of rocks, advanced drag reduction, strengthening sand consolidation, reducing the interfacial tension and increasing the mobility of the capillary-trapped oil [8].

In the past decade, most investigations have shown that nanoparticles (NPs) offer promise for future EOR processes where silica-based NPs have been most commonly used [9-13]. Although the oil displacement mechanism via NPs is not yet clearly understood [14-16], the nanotechnology is now chosen as an alternative method to unlock the remaining oil resources and applied as a new EOR method in last decade [10-12, 17-20]. polymeric microspheres and nanospheres have been applied as water mobility control both as a pilot and full-field, and showed fantastic results in reducing water cut, increasing sweep efficiency and improving oil recovery [21-23]. They reported that polymeric microspheres and nanospheres can swell when meet with water and then reduce water permeability due to its ability of reducing the capillary force and change water flow path. Consequently water goes into bypassed area and enhances displacement efficiency. Tian et al. also reported that polymeric microspheres and nanospheres have some advantages such as no degradation at high temperature and salinity. Some papers also address experiments where combinations of nanoparticles and surfactant solutions are tested. Le et al. studied synergistic blends of $\mathrm{SiO}_{2}$ nanoparticles and surfactants for EOR in high-temperature reservoirs.

Resasco et al. [24] showed that in case nanoparticles and anionic surfactants are used at the same time, IFT reduction is $70 \%$ more than when the surfactant is used alone. Obviously, IFT becomes ultra low or reaches almost zero using nanohybrid and surfactant at the same time. In addition to previous applications of nanotechnology in petroleum upstreams, enormous researches have been made on the title of implementing of nano-particles on the EOR from petroleum reservoirs [25]. Hence, in some studies the applications of nanoparticles in oil industry have been reported and classified based on priority. Researchers have concluded that nanotechnology has the greatest usage in chemical EOR methods [26]. Therefore, in some studies, the role of nanoparticles in EOR operations has been reported [27-29]. Table 1 shows some nano particles utilized for enhanced oil recovery in IFT process [30].

The objective of this paper is to investigate the potential of nano particles in chemical flooding for oil recovery. This study reviewed and assessed some of the recent advances. Specifically, it aims to explain the contributions of application nano in the polymer and surfactant flooding on the interfacial tension process and also overall incremental oil recovery.

\section{Enhanced oil recovery}

Oil production has three different stages: primary (production by natural reservoir energy), secondary (on the supply of external energy into the reservoir in the form of injecting fluids to increase reservoir pressure) and tertiary production (enhanced oil recovery methods increase the mobility of the oil to increase production). Over the lifetime of the oil field the pressure will fall, and at some point there will be insufficient underground pressure to lift the oil to the surface. To maintain the reservoir pressure, and sweep out oil in a more efficient way, water flooding as secondary oil production is a practical and effective way for many reservoir formations. A problem with water flooding is that in many cases oil has higher viscosity than water, and this however may lead to an unstable displacement. Increasing the viscosity of injected water by adding a polymer or chemical agent will improve sweep during water flooding process. It is necessary to study and evaluate the rheological properties of the polymers before implementation as polymer flooding [31]. In enhanced oil recovery a dilute aqueous solution of polymer or surfactant is used as a pushing fluid in the injection wells to sweep oil in the reservoir into the production well. Mobility reduction or viscosity behaviour of polymer solutions plays an important role in such applications. The properties of polymer or surfactant in aqueous solutions have been widely investigated in the past decade [32-40].

\section{Chemical flooding}

Chemical injection or usually known as chemical flooding was, up to 2000's, less common EOR method than thermal and gas but now, huge projects are initiated or revisited. This involves injection of three kinds of chemicals that are alkaline, surfactant and polymer. Each chemical has unique functions and usually is used coincide. Three methods involving these chemicals are polymer, surfactant-polymer 
Table 1 List of studies carried out on EOR via nanofluids [30]

\begin{tabular}{|c|c|c|c|c|}
\hline References & NP type & NP conen & Dispersion medium & Porous media \\
\hline Onyekonwu and Ogolo (2010) & $\begin{array}{l}\text { Hydrophilic, neutralized, and } \\
\text { hydrophobic silica }\end{array}$ & $0.2-0.3 \mathrm{wt} \%$ & Ethanol and water & Sandstone cores \\
\hline Suleimanov et al. (2011) & Non-ferrous metal nanoparticles & $0.001 \mathrm{wt} \%$ & $\begin{array}{l}\text { Sulfanole alkyl aryl } \\
\text { sodium sulfonate }\end{array}$ & Quartz sand \\
\hline Shahrabadi et al. (2012) & Hydrophobic silica & $0.1-0.4 \mathrm{wt} \%$ & Ethanol & Sandstone cores \\
\hline Karimi et al. (2012) & Zirconium oxide & 5 and $10 \mathrm{wt} \%$ & $\begin{array}{l}\text { mixture of nonionic } \\
\text { surfactant (Tween } 80+ \\
\text { Span } 85+\text { glycerin) and } \\
\text { DIW }\end{array}$ & Carbonate cores \\
\hline Hendraningrat et al. (2013) & Hydrophilic silica & $\begin{array}{l}0.01,0.05 \text {, and } \\
0.1 \mathrm{wt} \%\end{array}$ & Brine $(\mathrm{NaCl} 3 \mathrm{wt} \%)$ & $\begin{array}{l}\text { Berea sandstone } \\
\text { cores }\end{array}$ \\
\hline Zaid et al. (2013) & Zinc oxide and aluminum oxide & $0.05 \mathrm{wt} \%$ & $\begin{array}{l}\text { Mixture of sodium } \\
\text { dodecyl sulfate and } \\
\text { DIW }\end{array}$ & Glass bead \\
\hline Koustaei et al. (2013) & Hydrophobic silica & $0.1-0.4$ wt $\%$ & Ethanol & Sandstone cores \\
\hline Ehtesabi et al. (2014) & Titanium dioxide & 0.01 and $1 \mathrm{wt} \%$ & Brine $(\mathrm{NaCl} 0.5$ wt $\%)$ & Sandstone cores \\
\hline $\begin{array}{l}\text { Hendraningrat and Torsaeter } \\
\text { (2014) }\end{array}$ & $\begin{array}{l}\text { Aluminum oxide, titanium } \\
\text { dioxide, and silica }\end{array}$ & $0.05 \mathrm{wt} \%$ & Brine $(\mathrm{NaCl} 3 \mathrm{wt} \%)$ & Sandstone cores \\
\hline
\end{tabular}

(SP) and alkaline-surfactant-polymer flooding (ASP), and surely the most important substance in these methods is polymer [41].

\section{Polymer}

Polymer flood is the most widely used chemical EOR method. By adding polymers to water, the water-oil mobility is lowered. Such a change can lead to better sweep efficiency. It is generally believed that polymer flooding cannot reduce the residual oil saturation, but it can help to reach residual oil saturation in shorter time [42].

Polymer flood was proved technically and economically successful in many EOR projects worldwide [43, 44]. In field applications, polymer floods increased recovery by 12-15\% [45]. The field experiences in China showed that polymer flood was cheaper than water flood, due to increased oil output and reduced costs in water injection and treatment [46]. Currently, polymer flooding is considered as one of the most promising technologies in EOR process because of its technical and commercial feasibility. Particularly, the interest on polymer flooding applications worldwide has been stimulated by the outstanding results reported from the large-scale polymer flooding application in the Daqing oil field in China, with incremental oil productions of up to 300,000 barrels per day [47].

In practice, two commercial polymers, hydrolyzed polyacrylamides (HPAM) and xanthan gums, are commonly used in oil field applications. HPAM is a watersoluble polyelectrolyte with negative charges on the polymer chains. Xanthan gums, which are polysaccharides, show excellent viscosifying ability, high tolerance to salinity, and temperature [48].

However, the current widely used polymers, polyacrylamide (PAM) and partially hydrolyzed polyacrylamide (HPAM), cannot completely meet the requirements due to the hydrolysis, degradation, and others under high temperature or high salinity [49]. Furthermore, PAM and HPAM have poor shear resistance [50-53]. Polymer molecular chains will be cut off when polymer solution passes through the pump, pipeline, perforation, and porous medium at high speed, so the viscosity of polymer solution will be greatly reduced [53, 54]. Polymer viscosity was seriously affected by salinity. The effect of shearing on polymer viscosity and oil recovery was significant. Thus, high concentration of polymer was utilized to maintain high viscosity [55].

\section{Surfactant}

The surfactant-based chemical flooding processes are normally employed to recover the trapped, residual oil after the waterflooding. Numerous patents exist on evaluating different factors, which may affect the performance of these processes [56].

Surfactant flooding is one of the main mechanisms of reducing interfacial tension between oil and water for the purpose of enhancing oil recovery. Essentially, two different approaches have been developed for using surfactants to enhance oil recovery. 
In the surfactant flooding, a solution containing a low concentration of surfactant is injected. The surfactant is dissolved in either water or oil and in equilibrium with aggregates of the surfactant known as micelles. Large pore volumes (about $15-60 \%$ or more) of the solution are injected into the reservoir to reduce interfacial tension between oil and water and, thereby, increase oil recovery. Oil may be banked with the surfactant solution process, but residual oil saturation at a given position in the reservoir will only approach zero after passage of large volumes of surfactant solution. In the second approach, a relatively small pore volume (about 3-20\%) of a higher surfactant concentration solution is injected into the reservoir. The high surfactant concentration allows the amount of dispersed phase in the micro emulsion to be high as compared with the low value in the dispersed phase of the micelles in the low concentration surfactant solutions. The infected slug is formulated with three or more components. The initial components (hydrocarbon, surfactant, and water) are sufficient to form the micellar solutions. A co-surfactant as the fourth component (usually alcohol) can be added. Electrolytes, normally inorganic salts, form a fifth component that may be used in preparing the micellar solutions or microemulsions. The high concentration surfactant solutions displace both oil and water. As the high concentration slug moves through the reservoir, it is diluted by the formation's fluids and the process reverts to a lowconcentration flood. There are numerous mathematical modeling and experimental studies of various aspects of surfactant flooding in the literature [57-63].

Le and his colleagues performed experiments blending different types of surfactants with $\mathrm{SiO}_{2}$ nanoparticles. Some of the blends showed great potential for EOR application because of their resistance to adsorption onto the rock surface, and thermostability at $91{ }^{\circ} \mathrm{C}$ [64]. Suleimanov et al. carried out experiments which showed how dispersed nanoparticles in an aqueous phase could modify the interfacial properties of a liquid/liquid system, if their surface were modified by the presence of an ionic surfactant. The application of nanosuspension in their study permitted significant increase in the efficiency of oil displacement flow rate. In homogeneous pore media, oil recovery before water breakthrough was increased by 51 and $17 \%$ for surfactant aqueous solution with nanoparticle addition respectively to water and surfactant aqueous solution [65].

\section{Surfactant-polymer}

Surfactant-polymer (SP) flooding processes involve the injection of a surfactant-polymer slug followed by a polymer buffer and chase water injection. If designed correctly, the surfactant increases the capillary number, which is crucial for the mobilization and recovery of tertiary oil. Polymer increases the sweep efficiency by lowering the mobility ratio. If the reservoir crude oil has sufficient saponifiable components, soap (surfactant) is generated in situ by the reaction of these components with the injected alkali, thus adding more surfactant to the flood [66]. Surfactant-polymer interactions in solution are important with regard to the flow behavior in the porous media and the potential to displace the oil [67, 68]. Furthermore, the surfactant-polymer interaction at the solid/ liquid interface is extremely important with respect to the loss of chemicals by adsorption onto the minerals of the rock material. The loss of surfactant by adsorption is one of the main factors prohibiting, on economic grounds, the use of surfactants in field applications. In recent years, much attention, both experimental and theoretical, has been focused on surfactant-polymer interactions in solution, and several reviews have been published [69-72]. Alkali free SP flooding avoids the drawbacks associated with alkali. Surfactants with concentrations higher than the critical micelle concentration (CMC) can achieve ultra-low IFT. However, such surfactants are expensive. The use of a hydrophilic surfactant mixed with a relatively lipophilic surfactant or a new surfactant was also investigated [7375]. However, studies on SP flooding only focused on the screening and evaluation of the polymer and surfactant and their interaction. Reduction in mobility ratio and IFT is influenced by reservoir brine salinity, reservoir temperature, concentration of chemical ingredients an oil components, and others [76-79].

\section{Interfacial tension measurement}

The IFT between the equilibrated brine and oil phases was measured with the help of a spinning drop tensiometer. In cases where third phase micro-emulsion was found to exist, oil phase was taken near the middle phase for accurate measurement of the IFT. Optimal salinity was taken as the salinity of the system which gave the least IFT between the oil and the aqueous phase. It was always near the salinity where the middle phase microemulsion was present in the phase behavior studies. The subsequent wettability experiments were performed at the optimal salinity obtained from these measurements [80].

\section{Effects of nanoparticles on IFT reduction}

Role of the surfactant is to lower the interfacial tension and to form an initial dispersion of air/water or oil/water in case of foam or emulsion, respectively. Once this dispersion is 
formed due to shear and a decreased amount of interfacial tension, the stability of foam/emulsion is augmented by adsorption of nanoparticles at the interface [81]. For example, usage of silica nanoparticles coated with a polyelectrolyte to stabilize oil-in-water emulsions has been reported. More recently, Saigal et al. [82], reported stable oil-in-water emulsions using silica nanoparticles coated with a $\mathrm{pH}$ responsive polymer, and they found that the most stable emulsions were formed at lower polymer chain grafting densities. In addition, some researchers investigated about the effects of nanoparticles on IFT reduction on surfactant solutions [83]. They claimed that the presence of nanoparticles changes rheological properties and increases the effect of surfactant solution on oil recovery processes. First of all, it changes interfacial tension value of surfactant/oil interface more effectively [84]. Observed reduction of interfacial tension is the result of nanoparticles presence at the interfacial layers. In low concentrations of nanoparticles, they are attached to the liquid surface and due to absorption process surface tension decreases. However, in high concentrations, the nanoparticles nearly completely remove the surfactant from the bulk aqueous phase and there is no free surfactant available in the bulk. Thus, for nanoparticles in low concentrations the interfacial tension of the dispersion is determined by a mixed layer composed of attached nanoparticles and surfactant adsorbed at the liquid interface [85]. Accordingly, the interfacial tensions values were determined in different states. All reported interfacial tension values were measured by a drop shape tensiometer DSA30 of Kruss company. Pendant drop-method based on the Laplace equation which describes relationship between the difference in pressure and interfacial tension was selected for our purpose. The results are shown in Table 2 .

As can be seen, nanoparticles decreased surface tension by $70 \%$ when used with a SDS concentration of 2000 ppm, while the figure for C12TAB was about $81 \%$. In addition, ZRSL3000 solution, which was chosen before as an optimum concentration, showed an IFT value of 17.1 (103 N/m). Seemingly, although this amount almost showed a same amount compared to both surfactants alone, it is by far more than nanoparticles/surfactant value. This means that nanoparticles along with surfactants can strongly decrease the interfacial tension of oil and water, which can lead to more stable emulsions and justify the enhancement of oil recovery. In this regard, SDS showed better performance than $\mathrm{C} 12 \mathrm{TAB}$ when used either alone or with nanoparticles [86].

Nanoparticles form a mixed layer with surfactants at the interface between the injected fluid and oil. This results in increasing the interface consequently makes a considerable contribution to reducing IFT. This means that capillary forces considerably decrease and capillary number will strongly be increased [75]. In fact, both nanoparticles and surfactants help each other to remain stable and to contribute to keeping the formed emulsions stable. The presence of suspended nanoparticles in the solution increases sedimentation stability, because surface forces easily counterbalance the force of gravity. In addition, it is obvious that surfactants contribute to the stability of nanoparticles and emulsions to decrease IFT [65, 87].

The influences of hydrophilic and slightly hydrophobic silica nanoparticles on sodium dodecyl sulfate anionic surfactant properties were investigated for enhancing oil recovery purpose. Surfactant interfacial and adsorption behaviors were investigated in the presence of nanoparticles. Considerably stable nanoparticle suspensions were obtained adding low amounts of sodium dodecyl sulfate. Opposing interfacial properties were observed for low to high surfactant concentrations for both hydrophilic and hydrophobic nanoparticle-augmented solutions. The inclusion of nanoparticles had a negligible influence on the oil/water interfacial tension at very low surfactant concentrations. However, surfactant efficiency was rather significantly improved at higher sodium dodecyl sulfate concentrations up to about CMC after which the oil/water interfacial tension began to grow. The interfacial tension eventually reached a constant value greater than the one obtained by the sole surfactant solution of the same concentration. Table 3 summarizes IFT of these surfactants with different nano concentration [88].

The results showed consistency with a relatively low deviation. The contact angle and interfacial tension (IFT) were measured and analyzed to determine the possible displacement mechanism. It was observed that the nanofluid rendered the quartz plate more water-wet in both

Table 2 Nano-particles effect on IFT reduction [86]

\begin{tabular}{|c|c|c|c|c|c|}
\hline \multicolumn{2}{|c|}{ Concentration (ppm) } & \multirow[t]{2}{*}{ IFT (10-3 N/m) } & \multicolumn{2}{|l|}{ Concentration (ppm) } & \multirow[t]{2}{*}{ IFT $(10-3 \mathrm{~N} / \mathrm{m})$} \\
\hline $\begin{array}{l}\text { Sodium dodecyl } \\
\text { sulfate (SDS) }\end{array}$ & Nanoparticles & & $\begin{array}{l}\text { Dodecyl trimethylammonium } \\
\text { bromide (C12TAB) }\end{array}$ & Nanoparticles & \\
\hline 2000 & 0 & 16 & 3000 & 0 & 18.4 \\
\hline 2000 & 100 & 3.1 & 3000 & 100 & 5.4 \\
\hline
\end{tabular}


Table 3 Summarizes IFT of these surfactants with different nano concentration [88]

\begin{tabular}{|c|c|c|c|}
\hline \multicolumn{2}{|c|}{ Concentration (ppm) } & \multicolumn{2}{|c|}{ Interfacial tension (dyne/cm) } \\
\hline Surfactant & Nanoparticle & Surfactant solution & Nanoparticle-augmented surfactant solution \\
\hline 500 & 1000 & 7.43 & 3.71 \\
\hline 500 & 2000 & 7.43 & 4.64 \\
\hline 1000 & 1000 & 3.53 & 2.59 \\
\hline 1000 & 2000 & 3.53 & 2.76 \\
\hline 2000 & 1000 & 2.60 & 1.87 \\
\hline 2000 & 2000 & 2.60 & 2.42 \\
\hline 4000 & 1000 & 2.90 & 3.64 \\
\hline 4000 & 2000 & 2.90 & 4.74 \\
\hline 6000 & 1000 & 2.85 & 4.26 \\
\hline 6000 & 2000 & 2.85 & 4.64 \\
\hline
\end{tabular}

wettability systems, and the presence of hydrophilic nanoparticles at a $0.05 \mathrm{wt} \%$ concentration was effective in altering the wettability between 15 and $33 \%$. The presence of NPs did not significantly reduce the IFT between the oleic- and aqueous-phase. Therefore, wettability alteration plays a more dominant role in the possible oil displacement mechanism using nano-EOR [20].

$\mathrm{SiO}_{2}$ nano-powder is a new type of augmented injection agent that has the ability of stronger hydrophobicity and lipophilicity, and can be absorbed on the rock surface leading to changes in the rock wettability level. It can be classified into two types: lipophobic and hydrophilic polysilicon nanoparticle (LHPN) and hydrophobic and lipophilic polysilicon nanoparticle (HLPN) [89, 90]. On the other hand, it can reduce the inter facial tension (IFT) between two phases, enhance oil effective permeability and reduce injection pressure and augment injection rate [91].

Ehtesabi et al. [92] researched about nano $\mathrm{TiO}_{2}$ on heavy oil recovery. Their results showed that $\mathrm{TiO}_{2}$ nanoparticles do not change significantly the viscosity and the interfacial tension. SEM images from the entrance side of the core plug after flooding test with $0.01 \% \quad \mathrm{TiO}_{2}$ nanoparticles confirm the coating of the rock surface with $\mathrm{TiO}_{2}$ nanoparticles (Fig. 1).

The capability of hydrophilic and slightly hydrophobic silica nanoparticles to improve surfactant performance was explored. Prior to flooding experiments, the effects of nanoparticle on surfactant properties were investigated. The results showed that interfacial tension between nanoparticle-augmented surfactant solution and oil starts with a rapid decrease in low surfactant concentration and follows an increase at higher concentrations. Surfactant adsorption on rock surface was generally reduced in the presence of nanoparticle and this reduction was much more considerable for hydrophobic particles in all surfactant concentrations [93]. A systematic study of hydrophilic metal oxide nanoparticles (NPs) for EOR purposes was performed, and the stability of metal oxide-based nanofluids was successfully improved by adding polyvinylpyrrolidone at $1 \mathrm{wt} \%$. The contact angle, interfacial tension (IFT) and effluent were measured and analysed in the displacement mechanism observations. It was observed that all nanofluids rendered the quartz plate more water-wet, and the $\mathrm{TiO}_{2}$-based nanofluid was the most effective wettability-altering fluid. This result is consistent with and proportional to the additional oil recovery from the coreflood experiment. The particle adsorption during the transport process was identified from the effluent analysis. The presence of nanoparticles reduced the IFT between the oleic phase and aqueous phase as did the presence of polyvinylpyrrolidone as dispersant, but the degree of IFT reduction is not proportional to the additional oil recovery. The lowest IFT was achieved by metal oxide nanoparticles even though this material does not have the lowest $\mathrm{pH}$. The additional oil recovery due to silica-based nanofluid is greater than that of brine with polyvinylpyrrolidone solution, even though the silica-based nanofluid has a higher IFT than the brine with polyvinylpyrrolidone solution [94]. A systematic study of hydrophilic metal oxide nanoparticles (NPs) for EOR purposes was performed, and the stability of metal oxidebased nanofluids was successfully improved by adding polyvinylpyrrolidone at $1 \mathrm{wt} \%$. Structure of PVP is shown in Fig. 2. Hydrophilic metal oxide nanoparticles (Fig. 3).

\section{Conclusion}

Nano particles can enhance the function ability of the stimulation fluids due to easy access of the nanos into the oil-water interface to reduce the IFT between the oil and the water and enhance the oil production [96]. 

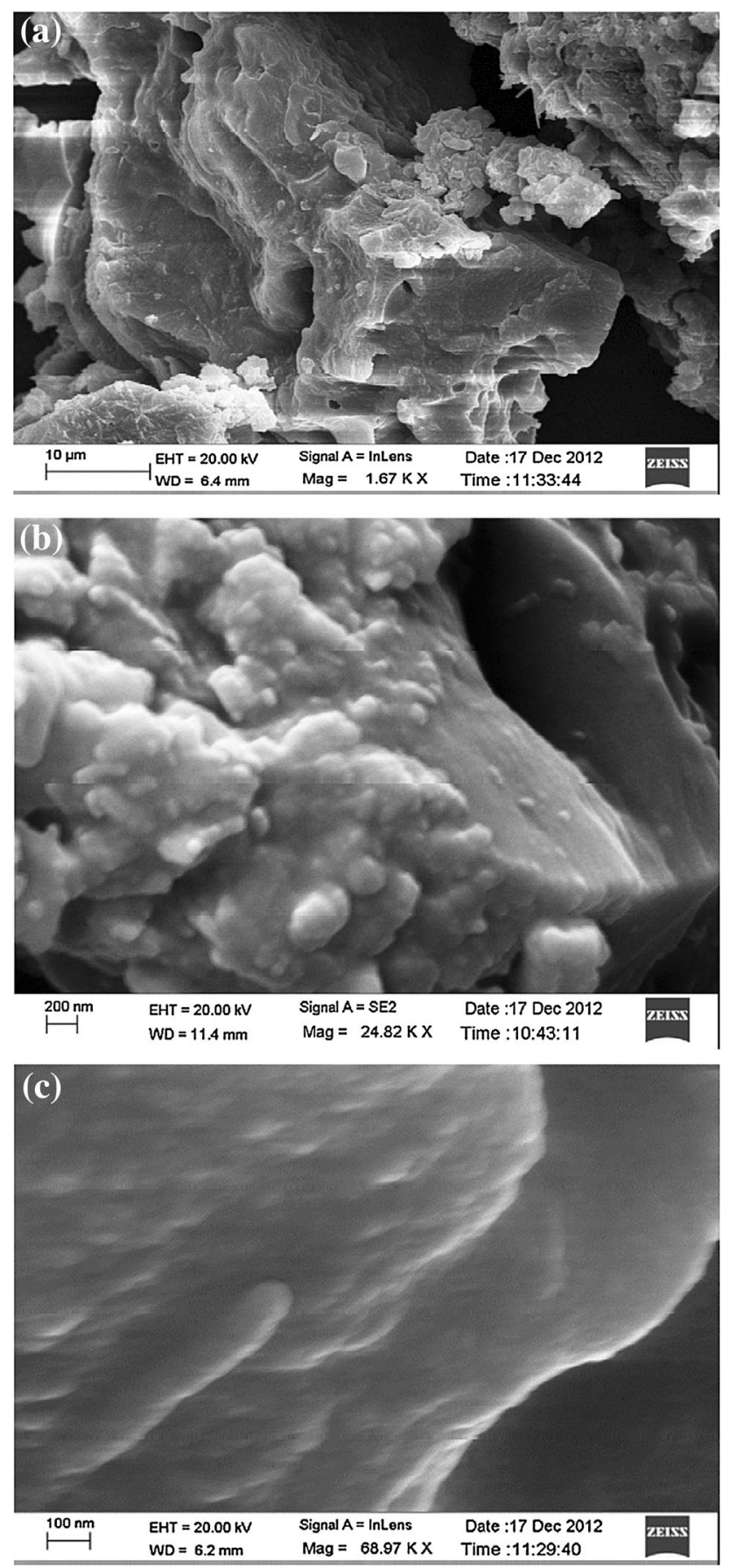

Fig. 1 The SEM images of core plug after flooding with $0.01 \%$ nanoparticles a $10 \mu \mathrm{m}$ scale and b $200 \mathrm{~nm}$ scale and c $100 \mathrm{~nm}$ scale [92]

Nanotechnology has the potential to have a positive effect on the chemical EOR process. The aims of this paper were firstly to compile an up-to-date data base for implemented nano chemical injection projects reported in the literature over the last 15 years. Altogether, nanotechnology can be an effective enhancement option for an oil

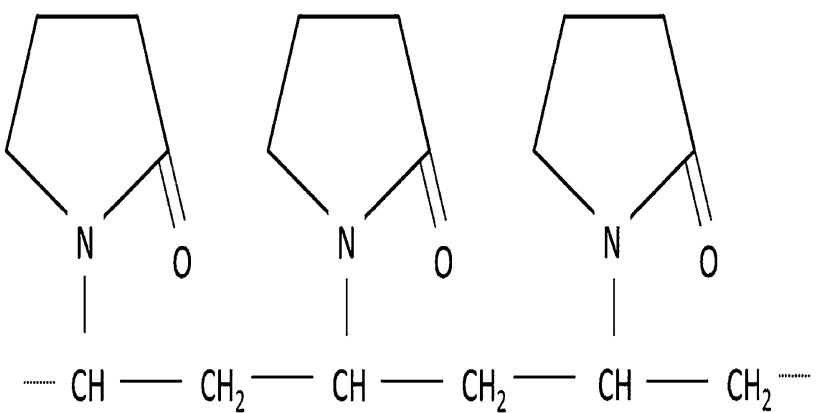

Fig. 2 Chemical structure of PVP [95]

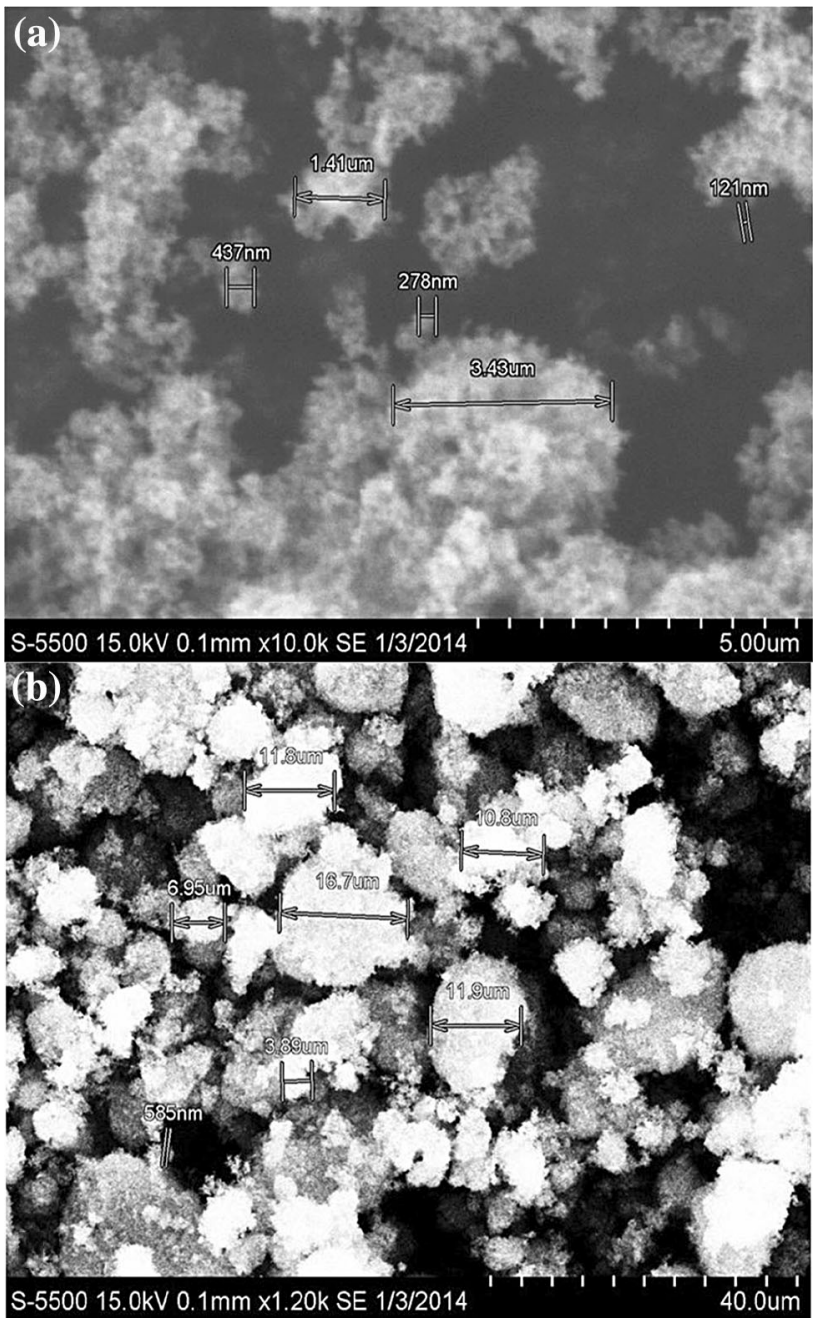

Fig. 3 Morphology and elemental analysis of $\mathbf{a} \mathrm{TiO}_{2}$ and $\mathbf{b} \mathrm{SiO}_{2} \mathrm{NPs}$ from SEM [94]

recovery method in a oil reservoir which is technically sensitive to the chemical recovery method. Although the future of nanotechnology is completely uncharted territory, but certainly nanotechnology will revolutionize the oil industry in several important ways. 
Open Access This article is distributed under the terms of the Creative Commons Attribution 4.0 International License (http://crea tivecommons.org/licenses/by/4.0/), which permits unrestricted use, distribution, and reproduction in any medium, provided you give appropriate credit to the original author(s) and the source, provide a link to the Creative Commons license, and indicate if changes were made.

\section{References}

1. Evdokimov, I.N., Eliseev, N.Y., Losev, A.P., Novikov, M.A.: Emerging petroleum-oriented nanotechnologies for reservoir engineering. In: Paper SPE 102060 presented at the SPE Russian Oil and Gas Technical Conference and Exhibition, Moscow, Russia, 3-6 Oct (2006)

2. Singh, S., Ahmed, R.,: Vital role of nanopolymers in drilling and stimulations fluid applications. In: Paper SPE 130413 presented at the SPE Annual Technical Conference and Exhibition, Florence, Italy, 19-22 Sept (2010)

3. Engeset, B.: The potential of hydrophilic silica nanoparticles for EOR purposes: a literature review and an experimental study. Master Thesis, Department of Petroleum Engineering and Applied Geophysics, Norwegian University of Science and Technology, Trondheim, Norway (2012)

4. Rodriguez, E., Roberts, M.R., Yu, H., Huh, H., Bryant, S.L.: Enhanced migration of surface-treated nanoparticles in sedimentary rocks. In: SPE Annual Technical Conference and Exhibition, New Orleans, Louisiana, USA (2009)

5. Kanj, M.Y., Funk, J.J., Al-Yousif, Z.: Nanofluid coreflood experiments in the ARAB-D. In: SPE Saudi Arabia Section Technical Symposium and Exhibition, AlKhobar, Saudi Arabia (2009)

6. Zhang, T.: Engineered nanoparticles as harsh-condition emulsion and foam stabilizers and as novel sensors. In: Offshore Technology Conference, Houston, Texas, USA (2011)

7. Mokhatab, S., Fresky, M.A., Islam M.R.: Application of Nanotechnology in Oil and Gas E\&P, JPT, Society of Petroleum Engineers, 18 April (2006)

8. Cheraghian, G., Khalili Nezhad, S., Kamari, M., Hemmati, M., Masihi, M., Bazgir, S.: Adsorption polymer on reservoir rock and role of the nanoparticles, clay and $\mathrm{SiO}_{2}$. Int. Nano Lett. 4, 114 (2014). doi:10.1007/s40089-014-0114-7

9. Ju, B., Fan, T., Ma, M.: Enhanced oil recovery by flooding with hydrophilic nanoparticles. China Part 4(1), 41-46 (2006)

10. Miranda C.R., De Lara L.S., Tonetto B.C.: Stability and mobility of functionalized silica nanoparticles for enhanced oil recovery application. The Society of Petroleum Engineers SPE 157033-MS (2012)

11. Roustaei, A., Saffarzadeh, S., Mohammadi, M.: An evaluation of modified silica nanoparticles' efficiency in enhancing oil recovery of light and intermediate oil reservoirs. Egypt. J. Pet. 22, 427-433 (2013)

12. Cheraghian, G.: Application of nano fumed silica in heavy oil recovery. Pet. Sci. Technol. (2015). doi:10.1080/10916466.2015. 1114497

13. Hendraningrat, L., Li, S., Torsæter, O.: Enhancing oil recovery of low-permeability berea sandstone through optimised nanofluids concentration. In: SPE Enhanced Oil Recovery Conference, Kuala Lumpur, Malaysia (2013)

14. Wasan, D.T., Nikolov, A.: Spreading of nanofluids on solids. Nature 423, 156-159 (2003)

15. Wasan, D.T., Nikolov, A.: Kondiparty, K. The wetting and spreading of nanofluids on solids: role of the structural disjoining pressure. Curr. Opin. Colloid Interface Sci 16, 344-349 (2011)

16. Chengara, A., Nikolov, A., Wasan, D.T., Trokhymchuck, A., Henderson, D.: Spreading of nanofluids driven by the structural disjoining pressure gradient. J. Colloid Interface Sci. 280, 192-201 (2004)

17. Ju, B., Tailiang, F., Mingxue, M.: Enhanced oil recovery by flooding with hydrophilic nanoparticles. China Particuol. 4, 41-46 (2006)

18. Ogolo, N.A., Olafuyi, O.A.: Onyekonwu MO Enhanced oil recovery using nanoparticles. The Society of Petroleum Engineers SPE 160847-MS (2012)

19. Hendraningrat, L., Torsæter, O.: Metal oxide-based nanoparticles: revealing their possibility to enhance the oil recovery at different wettability systems. Appl. Nano Sci. Springer. (2014). doi:10.1007/s13204-014-0305-6

20. Cheraghian, G.: Effects of nanoparticles on wettability: a review on applications of nanotechnology in the enhanced oil recovery. Int. J. Nano Dimens. 6(5), 443-452 (2015). doi:10.7508/ijnd. 2015.05.001

21. Cheraghian, G., Hemmati, M., Masihi, M., Bazgir, S.: An experimental investigation of the enhanced oil. J. Nano. Chem. 3, 78 (2013). doi:10.1186/2193-8865-3-78

22. Cheraghian G., Tardasti S.: Improved oil recovery by the efficiency of nano-particle in imbibition mechanism. In: 74th EAGE Conference and Exhibition incorporating EUROPEC. (2012). doi:10.3997/2214-4609.20148913

23. Tian, Y., Wang, L., Tang, Y., Liu, C., Ma, C., Wang, T.: Research and application of nano polymer microspheres diversion technique of deep fluid. The Society of Petroleum Engineers SPE 156999-MS (2012)

24. Resasco, D., Drexler, S., Harwell, J.H., Shiau, B.J., Kadhum, M.J.: Method and foam composition for recovering hydrocarbons from a subterranean reservoir, Pub. No: WO 2013/052359 Al (2013)

25. Hendraningrat, L., Engeset, B., Suwarno, S., Torsæter, O.: Improved oil recovery by nanofluids flooding: an experimental study. In: SPE Kuwait International Petroleum Conference and Exhibition, Kuwait City, Kuwait (2012)

26. Pourafshary, P., Azimipour, S.S., Motamedi, P., Samet, M., Taheri, S.A., Bargozin, H., Hendi, S.S.: Priority assessment of the investment in development of nanotechnology in upstream petroleum industry. In: Proceedings of the Saudi Arabia Section Technical Symposium and Exhibition. A1Khobar, Saudi Arabia, SPE No. 126101-MS (2009)

27. Skauge, T., Hetland, S., Spildo, K., Skauge, A.: Nano-sized particles for EOR. In: SPE 129933, SPE Improved Oil Recovery Symposium, Oklahoma, USA, 24-28 April (2010)

28. Cheraghian, G.: An experimental study of a surfactant polymer for enhanced heavy-oil recovery using a glass micromodel by adding nanoclay. Pet. Sci. Technol. 33(13-14), 1410-1417 (2015)

29. Cheraghian, G., Khalili Nezhad, S., Kamari, M., Hemmati, M., Masihi, M., Bazgir, S.: Effect of nanoclay on improved rheology properties of polyacrylamide solutions used in enhanced oil recovery. J. Pet. Explor. Prod. Technol. (2014). doi:10.1007/ s13202-014-0125-y

30. Esfandyari Bayat, A., Junin, R., Samsuri, A., Piroozian, A., Hokmabadi, M.: Impact of metal oxide nanoparticles on enhanced oil recovery from limestone media at several temperatures. Energy Fuels 28(10), 6255-6266 (2014)

31. Sorbie, K.S.: Polymer improved oil recovery. Blackie and Son Ltd, Glasgow (1991)

32. Rinaudo, M., Milas, M., Jouon, N., Borsali, R.: On some original properties of dilute polyelectrolyte solutions at low salt content: sodium hyaluronate example. Polymer 34, 3710-3715 (1993)

33. Muller, K.K., Vilgis, T.A.: Dynamics of dense polyelectrolyte solutions. Macromolecules 31, 5898-5903 (1998)

34. Antonietti, M., Briel, A., Forster, S.: Quantitative description of the intrinsic viscosity of branched polyelec-trolytes. Macromolecules 30, 2700-2704 (1997) 
35. Leibler, L., Pezron, E.: Viscosity behaviour of polymer solutions in the presence of complexing ions. Polymer 29, 1105-1109 (1988)

36. Ennari, J., Elomaa, M., Sundholm, F.: Modelling a polyelectrolyte system in water to estimate the ion-conductivity. Polymer 40, 5035-5041 (1999)

37. Vishalakshi, B., Ghosh, S., Kalpagam, V.: The effects of charge density and concentration on the composition of polyelectrolyte complexes. Polymer 34, 3270-3275 (1993)

38. Dobrynin, A.V., Colby, R.H., Rubintein, M.: Scaling theory of polyelectrolyte solutions. Macromolecules 28, 1859-1871 (1995)

39. Zeynali, M., Rabii, A., Baharvand, H.: Synthesis of partially hydrolyzed polyacrylamide and investigation of solution properties (viscosity behaviour). Iran. Polym. J. 13(6), 479-484 (2004)

40. Jousset, S., Bellissent, H., Galin, J.C.: Polyelectrolytes of high charge density in organic solvent: synthesis and viscometric behavior. Macromolecules 31, 4520-4530 (1998)

41. Abidina, A.Z., Puspasaria, T., Nugroho, W.A.: Polymers for enhanced oil recovery technology. Proc. Chem. 4, 11-16 (2012). doi:10.1016/j.proche.2012.06.002

42. Du, Y., Guan, L.: Field-scale polymer flooding: lessons learnt and experiences gained during past 40 years. In: SPE 91787 Presented at SPE International Petroleum Conference, Puebla, Mexico, 8-9 Nov (2004)

43. Cheraghian, G., Khalili Nezhad, S.S.: Effect of nanoclay on heavy oil recovery during polymer flooding. Pet. Sci. Technol. 33(9), 999-1007 (2015)

44. Sheng, J.: Modern Chemical Enhanced Oil Recovery: Theory and Practice, pp. 101-111. Gulf Professional Publishing, Oxford,UK (2011)

45. Wang, D., Cheng, J., Wu, J., Wang, Y.: Producing by polymer flooding more than 300 million barrels of oil what experiences have been learnt. In: SPE 77872 presented at Asia Pacific oil and Gas Conference and Exhibition, Melbourne, Australia, 8-10 Oct (2002)

46. Wang, D., Zhao, L., Cheng, J., Wu, J.: Actual field data show that production costs of polymer flooding can be lower than water flooding. In: SPE 84849 Presented at Improved Oil Recovery Conference in Asia Pacific, Kuala Lumpur, Malaysia, 20-21 Oct, Publishing, pp 101-206 (2003)

47. Wang, D.M., Xia, H.F., Liu, Z.C., Yang, Q.Y.: Study on the mechanism of polymer solution with viscous-elastic behavior increasing microscopic oil displacement efficiency, Acta Petrolei Sinica 22 (4), 60-65, (2001)

48. Guo, XH, Li., D.W., Tian, J., Liu, YZ.: Pilot test of xanthan gum flooding in Shengli oilfield. In: SPE 57294 Presented at SPE Asia Pacific Improved Oil Recovery Conference, Kuala Lumpur, 25-26 Oct (1999)

49. Ye, Z.B., Gou, G.J., Gou, S.H., Jiang, W.C., Liu, T.Y.: Synthesis and characterization of a water-soluble sulfonates copolymer of acrylamide and $N$-Allylbenzamide as enhanced oil recovery chemical. J. Appl. Polym. Sci. 128(3), 2003-2011 (2013)

50. Shiran, B.S., Skauge, A.: Enhanced oil recovery (EOR) by combined low salinity water/polymer flooding. Energy Fuels 27(3), 1223-1235 (2013)

51. Cheraghian, G., KhaliliNezhad, S., Bazgir, S.: Improvement of thermal stability of polyacryl amide solution used as a nano-fluid in enhanced oil recovery process by nanoclay. Int. J. Nanosci. Nanotechnol. 11(3), 201-208 (2015)

52. Ye, Z., Qin, X., Lai, N., Peng, Q., Li, X., Li, C.: Synthesis and performance of an acrylamide copolymer containing nano- $\mathrm{SiO}_{2}$ as enhanced oil recovery chemical. Hindawi Publ. Corp. J. Chem. (2013). doi:10.1155/2013/437309

53. Cheraghian, G.: Thermal resistance and application of nanoclay on polymer flooding in heavy oil recovery. Pet. Sci. Technol. 33(17-18), 1580-1586 (2015)
54. Xue, L., Agarwal, U.S., Lemstra, P.J.: Shear degradation resistance of star polymers during elongational flow. Macromolecules 38(21), 8825-8832 (2005)

55. Wu, Z., Yu, J., Cheng, T., Yue, X., Yang, H.: Effect of viscosity and interfacial tension of surfactant-polymer flooding on oil recovery in high-temperature and high-salinity reservoirs. J. Pet. Explor. Prod. Technol. 4, 9-16 (2014)

56. Yadali Jamaloei, B., Kharrat, R., Ahmadloo, F.: Selection of proper criteria in flow behavior characterization of low tension polymer flooding in heavy oil reservoirs. In: SPE Kuwait International Petroleum Conference and Exhibition. Kuwait City, Kuwait (2009)

57. Raterman, K.T., Kremesec, Jr., V.J., Suffridge, F.E., Evaluation of low-concentration surfactant flooding in the absence of mobility control agents. In: SPE/DOE Paper No. 17394. SPE/ DOE Enhanced Oil Recovery Symposium, Tulsa, Oklahoma, 17-30 April (1988)

58. Sanz, C.A., Pope, G.A.: Alcohol-free chemical flooding: from surfactant screening to coreflood design. In: SPE Paper No. 28956. SPE International Symposium on Oilfield Chemistry, San Antonio, Texas, 14-17 Feb (1995)

59. Yang, H.D., Wadleigh, E.E.: Dilute surfactant IOR-design improvement for massive, fractured carbonate applications. In: SPE Paper No. 59009. 2000 SPE International Petroleum Conference and Exhibition, Villa Hermosa, Mexico, 1-3 Feb (2000)

60. Sanele, S., Yortsos, Y.C.: A note on the application of the theory of coherence to surfactant flooding. SPE Reserv. Eng. 1, 23-28 (1986)

61. Hornof, V., Morrow, N.R.: Gravity effects in the displacement of oil by surfactant solution. SPE Paper No. 13573. SPE Reserv. Eng. 2, 627-633 (1987)

62. Hematpour, H., Arabjamloei, R., Nematzadeh, M., Esmaili, H., Mardi, M.: An experimental investigation of surfactant flooding efficiency in low viscosity oil using a glass micromodel. Energy Sources Part A: Recov. Util. Environ. Effects 34(19), 1745-1758 (2012)

63. Esmaeilzadeh, P., Hosseinpour, N., Bahramian, A., Fakhroueian, Z., Arya, S.: Effect of $\mathrm{ZrO}_{2}$ nanoparticles on the interfacial behavior of surfactant solutions at air-water and $n$-heptane-water interfaces. Fluid Phase Equilib. 361, 289-295 (2014)

64. Le, N., Pham, D.K., Le, K.H., Nguyen, P.T. Design and screening of synergistic blends of sio2 nanoparticles and surfactants for enhanced oil recovery in high-temperature reservoirs. In: Advances in Natural Sciences: Nanoscience and Nanotechnology, vol. 2, published 21 July (2011)

65. Suleimanov, B.A., Ismailov, F.S., Veliyev, E.F.: Nanofluid for enhanced oil recovery. J. Pet. Sci. Eng. 78, 431-437 (2011)

66. Lake, L.W.: Enhanced Oil Recovery. Prentice-Hall Inc, Upper Saddle River (1989)

67. Austad, T., Fjelde, I., Veggeland, K., Taugbol, K.: Physicochemical principles of low tension polymer flood. J. Pet. Sci. Eng. 10, 255-269 (1994)

68. Taugbel, K., Ly, T.V., Austad, T.: Chemical flooding of oil reservoirs 3. Dissociative surfactant-polymer interaction with a positive effect on oil recovery. Colloids Surf. A: Physicochem. Eng. Aspects 103, 83-90 (1995)

69. Cheraghian, G., Effects of titanium dioxide nanoparticles on the efficiency of surfactant flooding of heavy oil in a glass micromodel, petroleum science and technology. doi:10.1080/ 10916466.2015.1132233

70. Goddard, E.D.: Polymer-surfactant interaction Part I. uncharged water-soluble polymers and charged surfactants, Colloids Surf. 19, 255-300 (1986)

71. Piculell, L., Lindman, B.: Adv. Colloid Interface Sci. 41, 149 (1992)

72. Lindman, B., Thalberg, K., Goddard, E.D., Ananthapadmanabhan, K.P. (eds.): Interactions of Surfactants with Polymers and Proteins, pp. 203-276. CRC Press, Boca Raton (1993) 
73. Aoudia, M., Al-Shibli, M.N., Al-Kasimi, L.H., Al-Maamari, R., Al-Bemani, A.: Novel surfactants for ultralow interfacial tension in a wide range of surfactant concentration and temperature. J. Surf. Deterg. 9, 287-293 (2006)

74. Cui, Z., Du, X., Pei, X., Jiang, J., Wang, F.: Synthesis of didodecylmethylcarboxyl betaine and its application in surfactantpolymer flooding. J Surf. Deterg. 15, 685-694 (2012)

75. Rosen, M.J., Wang, H., Shen, P., Zhu, Y.: Ultralow interfacial tension for enhanced oil recovery at very low surfactant concentrations. Langmuir 21, 3749-3756 (2005)

76. Ferdous, S., Ioannidis, M.A., Henneke, D.E.: Effects of temperature, $\mathrm{pH}$, and ionic strength on the adsorption of nanoparticles at liquid-liquid interfaces. J. Nanopart. Res. 14, 850 (2012)

77. Gong, H., Guiying, X., Zhu, Y., Wang, Y., Dan, W., Niu, M., Wang, L., Guo, H., Wang, H.: Influencing factors on the properties of complex systems consisting of hydrolyzed polyacrylamide/triton $\mathrm{x}-100 /$ cetyl trimethylammonium bromide: viscosity and dynamic interfacial tension studies. Energy Fuels 23, 300-305 (2009)

78. Cao, Y., Zhao, R., Zhang, L., Xu, Z., Jin, Z., Luo, L., Zhang, L., Zhao, S.: Effect of electrolyte and temperature on interfacial tensions of alkylbenzene sulfonate solutions. Energy Fuels 26, 2175-2181 (2012)

79. Zhang, H., Dong, M., Zhao, S.: Experimental study of the interaction between $\mathrm{NaOH}$, surfactant, and polymer in reducing court heavy oil/brine interfacial tension. Energy Fuels 26, 3644-3650 (2012)

80. Adibhatla, B., Mohanty, K.K..: Oil recovery from fractured carbonates by surfactant-aided gravity drainage: laboratory experiments and mechanistic simulations. In: SPE 99773, The 2006 SPE/DOE Symposium on Improved Oil Recovery held in Tulsa, Oklahoma, USA, 22-26 April (2006)

81. Worthen, A.J., Bryant, S.L., Huh, C., Johnston, K.P.: Carbon dioxide-in-water foams stabilized with nanoparticles and surfactant acting in synergy. AIChE J. 59, 3490-3501 (2013)

82. Saigal, T., Dong, H., Matyjaszewski, K., Tilton, R.D.: Pickering emulsions stabilized by nanoparticles with thermally responsive grafted polymer brushes. Langmuir 26, 15200-15209 (2010)

83. Al-Raoush, R.I., Willson, C.S.: A pore-scale investigation of a multiphase porous media system. J. Contam. Hydrol. 77, 67-89 (2005)

84. Munshi, A.M., Singh, V.N., Kumar, M., Singha, J.P.: Effect of nanoparticle size on sessile droplet contact angle. J. Appl. Phys. 103, 084315 (2008)
85. Ravera, F., Santini, E., Loglio, G., Ferrari, M., Liggieri, L.: Effect of nanoparticles on the interfacial properties of liquid/liquid and liquid/air surface layers. J. Phys. Chem. 110(39), 19543-19551 (2006)

86. Mohajeri, M., Hemmati, M., Sadat Shekarabi, A.: An experimental study on using a nanosurfactant in an EOR process of heavy oil in a fractured micromodel. J. Pet. Sci. Eng. 126, 162-173 (2015)

87. Qiu, F.: The Potential applications in heavy oil EOR with the nanoparticle and surfactant stabilized solvent-based emulsion. CSUG/SPE 134613. (2010)

88. Barati, N., Zargartalebi, M., Kharrat, R.: Influences of hydrophilic and hydrophobic silica nanoparticles on anionic surfactant properties: interfacial and adsorption behaviors. J. Pet. Sci. Eng. (2014). doi:10.1016/j.petrol.2014.04.010

89. Ju, B., Fan, T.: Experimental study and mathematical model of nanoparticle transport in porous media. Powder Technol. 192(2), 195-202 (2009)

90. Suleimanov, B.A., Ismailov, F.S., Veliyev, E.F.: Nanofluid for enhanced oil recovery. J. Pet. Sci. Eng. 78(2), 431-437 (2011)

91. Wang, K.L., Cheng Liang, S., Wang, C.C.: Research of improving water injection effect by using active $\mathrm{SiO}_{2}$ nanopowder in the low-permability oil field. Adv. Mater. Res. 92, 207-212 (2010)

92. Ehtesabi, H., Ahadian, M.M., Taghikhani, V.: Enhanced heavy oil recovery using $\mathrm{TiO}_{2}$ nanoparticles: investigation of deposition during transport in core plug. Energy Fuels 29(1), 1-8 (2015)

93. Zargartalebi, M., Kharrat, R., Barati, N.: Enhancement of surfactant flooding performance by the use of silica nanoparticles. Fuel 143, 21-27 (2015)

94. Hendraningrat, L., Zhang, J.: Polymeric nanospheres as a displacement fluid in enhanced oil recovery. Appl. Nano Sci. Springer (2015). doi:10.1007/s13204-014-0399-X

95. Folttmann, H.: Quadir A polyvinylpyrrolidone (PVP)—one of the most widely used excipients in pharmaceuticals: an overview. Drug Deliv. Technol. 8(6), 22-27 (2008)

96. Amanullah Md., Al-Tahini, A.M.: Nanotechnology: Its Significance in Smart Fluid Development for Oil and Gas Field Application. SPE No. 126102-MS (2009) 